\title{
Efficacy of Dietary Aloe vera Supplementation on Hepatic Cholesterol and Oxidative Status in Aged Rats
}

\author{
Beong Ou Lim ${ }^{1,6}$, Nak Sul SeOnG ${ }^{2}$, Ryo Won CHout ${ }^{1}$, Jong Dai KIM ${ }^{3}$, Hyeon Yong LeE ${ }^{3}$, \\ Sun Yeou KIM ${ }^{1}$, Byung Pal YU ${ }^{4}$, Tae Il JEON ${ }^{5}$ and Dong Ki PARK ${ }^{5,6}$ \\ ${ }^{1}$ Graduate School of East-West Medical Science, Kyung Hee University, \\ 1 Hoeki-Dong, Dongdaemoon-Ku, Korea \\ ${ }^{2}$ Crop Experiment Stations, RDA, Suwon 441-100, Korea \\ ${ }^{3}$ School of Biotechnology and Bioengineering, Kangwon National University, 200-701, Korea \\ ${ }^{4}$ Department of Physiology, University of Texas Health Science Center, San Antonio, Texas, USA \\ ${ }^{5}$ Department of Applied Biology and Chemistry and ${ }^{6}$ Research Institute of Cell Activation, Konkuk University, \\ Seoul 143-701, Korea
}

(Received August 19, 2002)

\begin{abstract}
Summary In the current study, we show the anti-oxidative and hypocholesterol effects of aloe vera in the liver. Male specific pathogen-free (SPF) Fischer 344 rats were randomly assigned to one of four groups: Group A (control) was fed test chow without aloe supplementation; Group B was fed a diet containing a 1\% (per weight basis) freeze-dried aloe filet; Group C was fed a diet containing a 1\% (per weight basis) charcoal-processed, freeze-dried aloe filet; and Group D was fed a diet containing a charcoal-processed freeze-dried, whole leaf aloe $(0.02 \%$ per weight basis) in the drinking water. Our results show that a life-long intake of aloe had superior anti-oxidative action against lipid peroxidation in vivo, as indicated by reduced levels of hepatic phosphatidylcholine hydroperoxide. Additional anti-oxidative action was evidenced by enhanced superoxide dismutase (SOD) and catalase activity in groups B and C. Furthermore, our study revealed that hepatic cholesterol significantly increased in the control group during aging in contrast to the aloe-supplemented groups, which showed approximately $30 \%$ lower cholesterol levels, thereby an effective hypocholesteremic efficacy. In this report, we suggest that life-long dietary aloe supplementation suppresses free radical-induced oxidative damage and age-related increases in hepatic cholesterol.
\end{abstract}

Key Words Aging, aloe vera, oxidative stress, phospholipid hydroperoxide, cholesterol

Aloe vera has been used for health, medical, and cosmetic purposes for many centuries (1-3). Currently, aloe vera is a popular skin emollient and is used as an aid in the treatment of skin injuries and burns (4). Literature also shows that the ingestion of aloe was implicated in the amelioration of several age-related diseases, e.g., diabetes $(5,6)$ and hypertension $(6)$. Herlihy et al. (7) reported in their comprehensive study that the lifelong ingestion of aloe at moderated levels (1\%) causes no apparent adverse effects in the rat. More recently, Ikeno et al. (8) showed that the life-long dietary supplementation of aloe suppresses many age-related disease processes in rats.

Aloe's anti-inflammatory property has been documented in various types of inflammation (9). Aloe vera has been tested for its anti-inflammation action and its suppression of damaging free radicals and other reactive oxidative species (ROS) (10). Aloe was found to inhibit the release of ROS from polymorphonuclear leukocytes (11-13) and suppress the oxidation of arachidonic acid (14). Additional evidence supporting the

\footnotetext{
*E-mail: beongou@khu.ac.kr
}

anti-oxidative action of ingested aloe came from data obtained on decreased lipid peroxide concentrations in young rats (15). These findings of the antioxidative action of aloe were recently documented by the isolation and characterization of a potent antioxidant from aloe leaves (16).

Aging processes are gradual and progressive timedependent changes that compromise an organism's ability to meet both internal and external disruptions. A good example of such disruptions is the age-related oxidative stress caused by both the endogenous and exogenous generation of free radicals to exacerbate tissue injury (17). To prevent such damage, endogenous primary defense scavenging enzymes exert a protective action as exemplified by superoxide dismutase (SOD), which catalyzes the dismutation of superoxide, and catalase (CAT) that hydrolyzes hydrogen peroxide formed from the dismutation reaction.

In the present study, we studied the effects of longterm aloe supplementation on the protective action against lipid damage and age-related increases in the hepatic cholesterol of aging rats. To assess age-related lipid peroxidation, we determined phophatidylcholine 
hydroperoxide $(\mathrm{PCOOH})$ as a sensitive, reliable indicator of oxidative lipid injury using CL-HPLC, which is developed to monitor active ROS activity $(18,19)$.

The aloe vera additions we used in this study were prepared under the careful supervision of Aloecorp (Harlingen, TX, USA). Detailed preparation procedures of the aloe vera samples were previously described $(8$, 15). Briefly, aloe vera filets were obtained by skinning the leaf, with care taken to avoid contamination of the gel from the outer layers. The filets were dried, blended, and immediately freeze-dried. The product was then finely ground and stored at $-20^{\circ} \mathrm{C}$ until used. For the charcoal-processed preparations, the whole leaf was subjected to routine procedures for commercial preparation, which included charcoal-filtration. The filtrate was freeze-dried, and care was taken to avoid the development of rancidity and possible breakdown of the aloe vera ingredients. Frozen aliquots of the freeze-dried products were shipped to Purina Test Diet Mills (St. Louis, MO, USA) for mixing and preparation of the test diets. The test diets were mixed every two months and air-shipped to the University of Texas Health Science Center. With the exception of air shipment, the diets were kept at $-20^{\circ} \mathrm{C}$ at all times until fed to the rats.

The specific pathogen-free (SPF) male Fischer 344 rats used this study were purchased as weanlings from Charles River Laboratories (Kingston, NY, USA). Upon arrival by air, the rats were housed in a SPF barrier facility where they were individually housed in plastic cages with wire mesh floors. The SPF status of the rats was maintained throughout their life. The standards operation procedures for the barrier and rat maintenance were described previously (20).

At six weeks of age, rats were randomly assigned to one of four groups: Group A (control) was fed test chow without aloe supplementation; Group B was fed a diet containing a $1 \%$ (per weight basis) freeze-dried aloe filet; Group C was fed a diet containing a 1\% (per weight basis) charcoal-processed, freeze-dried aloe filet; and Group D was fed a diet containing charcoal-processed freeze-dried, whole leaf aloe $(0.02 \%$ per weight basis $)$ in drinking water.

The food intake of each rat in every group was measured as described previously (20). For Group D, the drinking water was changed every three days, and replaced with freshly acidified water to which charcoalprocessed aloe vera was added. At 4 and 16 mo of age, rats from each group were anaesthetized using methoxyflurane. Major organs were excised, weighed, and prepared for biochemical analyses. A recent publication gives a complete pathological analysis of these rats $(8)$.

Total lipids were extracted from the liver by the method of Folch et al. (21). The CL-HPLC procedure for the quantification of phophatidylcholine hydroperoxide $(\mathrm{PCOOH})$ concentration was done by the method of Miyazawa et al. (22). Standards for $\mathrm{PCOOH}$ were prepared by oxidation of phosphtidylcholine using a method of Terao et al. (23).

Total superoxide dismutase (SOD) activity was determined by a method previously described (24) (i.e., mon- itoring the inhibition of cytochrome c reduction at 550 $\mathrm{nm}$ using the xantine and xantine oxidase system). One SOD unit was defined as the amount of enzyme that inhibited reduction of cytochrome $\mathrm{c}$ by $50 \%$. Liver catalase activity was determined spectrophotometrically by measuring the decomposition of hydrogen peroxide at $240 \mathrm{~nm}$. One catalase unit is defined as the amount of enzyme required to decompose $1.0 \mu \mathrm{mol}$ of $\mathrm{H}_{2} \mathrm{O}_{2}$ per min, $\mathrm{pH} 7.0$, at $25^{\circ} \mathrm{C}(25,26)$.

Liver total lipids were extracted and purified by the Folch method (21), and cholesterol was measured as described previously $(27,28)$. Briefly, total lipid was extracted using acetone-absolute ethanol $(1: 1)$, and the alkali was neutralized with $10 \%$ acetic acid. To $2 \mathrm{~mL}$ of the digitonin solution were added. After overnight standing at room temperature, the amount of isolated cholesterol was estimated using the Sperry and Merrill method (29).

Differences among the mean of the individual groups were assessed by one-way ANOVA with Duncan's multiple range test (SPSS 7.5, SPSS Institute, USA). Differences of $p<0.05$ were considered significant (30).

We determined that $\mathrm{PCCOH}$ is a sensitive, key indicator for oxidative injury because phopholipids are important structural and functional components of the biological system and are commonly recognized as a major target of lipid peroxidation. Thus, to determine the inhibitory effect of aloe on lipid peroxidation, the amounts of $\mathrm{PCOOH}$ formed in rats at 4 and 16 mo were examined. $\mathrm{PCOOH}$ levels were 2 times higher in the 16mo-old rats than in the 4-mo-old rats, indicating an age-related change (Table 1). The aloe-fed rats in groups B, C, and D showed significantly reduced $\mathrm{PCOOH}$ amounts at $4 \mathrm{mo}$ as compared to the control rats, Group A.

The anti-oxidative effect of aloe feeding was manifested in two major scavenging enzymes, namely, SOD and catalase. In the case of SOD activity, while rats in Group A showed reduced SOD activity levels with age, the aloe-fed rats in groups B, C, and D showed increased levels with age (Table 1). In particular, SOD levels were significantly higher in Group C rats at 4 mo of age.

In the case of catalase activity, Group $C$ rats showed the highest increase among the aloe-fed groups at $4 \mathrm{mo}$ of age, and this trend continued to $16 \mathrm{mo}$ of age.

The suppressive effect of aloe on hepatic cholesterol was not observed at the age of $4 \mathrm{mo}$, indicating that 2.5 mo-long aloe feeding exerts little effect. However, aloe vera supplementation was shown to significantly lower cholesterol levels at the age of $16 \mathrm{mo}$ (Fig. 1). This finding indicates that aloe vera supplementation has an effective suppressive action against age-related hypercholesterolemia.

Aloe vera dietary supplementation has long been claimed to exert beneficial effects on a wide variety of human diseases $(1,2,6,31)$. In the current study, we examined the anti-oxidative effects of the life-long feeding of aole vera on age-related lipid peroxidation. Our rational to study aloe is based on several criteria: 1) our continuous interest in the anti-oxidative compounds of 
Table 1. Effects of aloe vera on the amount of phosphatidylcholine hydroperoxide (PCOOH), catalase, and superoxide dismutase (SOD) in the liver of rat between ages 4 and 16 mo.

\begin{tabular}{|c|c|c|c|c|}
\hline Groups/Oxidative level & A & $\mathrm{B}$ & $\mathrm{C}$ & $\mathrm{D}$ \\
\hline \multicolumn{5}{|l|}{ PCOOH (pmol/mg protein) } \\
\hline $4 \mathrm{mo}$ & $14.4 \pm 1.3^{\mathrm{c}}$ & $9.8 \pm 0.9^{b}$ & $9.3 \pm 2.1^{\mathrm{b}}$ & $3.2 \pm 0.5^{\mathrm{a}}$ \\
\hline $16 \mathrm{mo}$ & $30.3 \pm 3.8^{\mathrm{c}}$ & $19.9 \pm 2.8^{b}$ & $3.2 \pm 0.5^{\mathrm{a}}$ & $17.6 \pm 2.4^{b}$ \\
\hline \multicolumn{5}{|l|}{ Catalase (IU/mg protein) } \\
\hline $4 \mathrm{mo}$ & $78.1 \pm 4.3^{\mathrm{a}}$ & $81.5 \pm 5.6^{\mathrm{a}}$ & $109.4 \pm 4.4^{\mathrm{b}}$ & $81.9 \pm 6.3^{\mathrm{a}}$ \\
\hline $16 \mathrm{mo}$ & $54.6 \pm 3.0^{\mathrm{a}}$ & $71.4 \pm 4.8^{\mathrm{b}}$ & $84.0 \pm 5.2^{\mathrm{b}}$ & $53.9 \pm 5.2^{\mathrm{a}}$ \\
\hline \multicolumn{5}{|l|}{ SOD (IU/mg protein) } \\
\hline $4 \mathrm{mo}$ & $1.6 \pm 0.1^{\mathrm{a}}$ & $1.9 \pm 0.1^{\mathrm{a}}$ & $2.3 \pm 0.1^{\mathrm{b}}$ & $1.6 \pm 0.1^{\mathrm{a}}$ \\
\hline $16 \mathrm{mo}$ & $1.2 \pm 0.1^{\mathrm{a}}$ & $1.8 \pm 0.1^{\mathrm{b}}$ & $1.9 \pm 0.2^{\mathrm{b}}$ & $1.6 \pm 0.1^{b}$ \\
\hline
\end{tabular}

Each value represents the mean \pm SEM of five rats. ${ }^{a-c}$ Mean values with different superscripts are significantly different in the same age group $(p<0.05)$. Group A (control) was fed test chow without aloe supplementation; Group B was fed a diet containing 1\% (on a day weight basis) freeze-dried aloe filet; Group C was fed a diet containing a 1\% (per weight basis) charcoal-processed, freeze-dried aloe filet; and Group D was given charcoal-processed freeze-dried, whole leaf Aloe vera $(0.02 \%$ per weight basis) in drinking water.

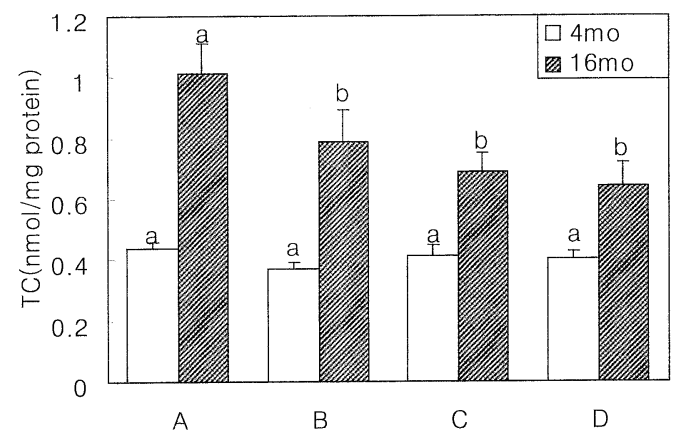

Fig. 1. Effects of aloe feeding on total cholesterol. Each bar represents the mean \pm SEM of five rats. $a, b$ : Mean values with different superscripts are significantly different in the same age group $(p<0.05)$. Group A (control) was fed test chow without aloe supplementation; Group B was fed a diet containing a 1\% (per weight basis) freeze-dried aloe filet; Group C was fed a diet containing a $1 \%$ (per weight basis) charcoal-processed, freeze-dried aloe filet; and Group D was fed a diet containing charcoal-processed freeze-dried, whole leaf aloe (0.02\% per weight basis) in drinking water.

natural products, for example, our previous findings of their protective value against membrane phospholipid peroxidation $(18,32-36) ; 2)$ previous studies showing the potential anti-oxidative property of aloe $(7,15,16)$; and 3) evidence of the putative cholesterol-lowering effect by aloe ingestion in humans with heart disease (6). Our current study attempted to document the antioxidative effect of life-long aloe ingestion on a biological system. In addition, we examined the anti-oxidative activities of various aloe preparations processed by different methods.

Our current data clearly demonstrated that dietary aloe supplementation decreases age-related oxidative stress, as evidenced by the reduced phosphstidylcholine hydroperoxide levels in both age groups (Table. 1). Our findings are in agreement with two previous reports showing the suppression action of aloe against age- related oxidative stress. This observation is significant in view of the putative anti-inflammatory property of aloe when administered in vitro $(14,31-33)$, when topically applied (10), and when ingested (37). Because inflammation processes involve the mediation of ROS and proinflammatory prostaglandins, the anti-oxidative action we observed in the current study may be the underlying mechanism for aloe's claimed anti-inflammatory actions.

Additional evidence showing the anti-oxidative action of aloe was in its ability to enhance two major free-radical scavenger enzymes, namely SOD and catalase. Oxidative stress is known to weaken defense systems during aging, including these two enzymes (38). Our current results show that aloe feeding enhanced catalase in groups B and C in 16-mo-old rats (Table 1), suggesting the possible maintenance of an anti-stress strategy against age-related oxidative insults. Such a possibility was shown by the reduced amount of lipid hydroperoxides (Table 1).

The cholesterol concentration was shown to increase with age in rat liver (Fig. 1). At 16 mo of age, the concentration was significantly lower in the aloe-supplemented groups as compared to the control group. The decrease in liver cholesterol observed in this study is consistent with the previous findings of our laboratory $(7,15)$, where reduced serum cholesterol was found in rats fed aloe for $7 \mathrm{mo}$. Our current results from 16-molong feeding data are much clearer and more convincing.

Our research demonstrated that the life-long ingestion of aloe exerts substantial benefits by attenuating the lipid peroxidation of phospholipids, lowering liver cholesterol, and enhancing antioxidant enzyme activity during aging. We concluded that aloe vera protects against age-related increases in oxidative stress in vivo. It is speculated that, at present, some active antioxidants in aloe as reported by Lee et al. (16), are responsible for its anti-oxidative action. We further suggest the possibility that aloe vera can be potentially beneficial 
against oxidative injury to the liver. Future investigations on the exploration of the anti-oxidative effects of aloe ingestion on aging and the modulation of antiinflammatory processes and wound healing at the cellular and molecular levels is warranted.

\section{Acknowledgments}

This work was supported by grants from the grant from BioGreen 21 Program the rural development administration, Republic of Korea. Authors acknowledge the support of Aloe Research Foundation (Harlingen, TX) for providing the aloe materials.

\section{REFERENCES}

1) Haller Jr., J.S. 1990. A drug for all seasons. Medical and Pharmacological history of aloe. Bull NY Acad Med 66: 647-659.

2) Grindlay D. Reynolds T. 1986. The aloe vera phenomenon: a review of the properties and modern uses of the leaf parenchyma gel. J Ethnopharmacol 16: 117-151.

3) Blitz JJ, Smith JW, Gerard JR. 1963. Aloe vera gel in peptic ulcer therapy: preliminary report. J Am Osteopath Assoc 62: 731-735.

4) Davis RH. 1997. Aloe Vera: Scientific Approach. Vantage Press, New York.

5) Ghannam N, Kingston M, Al-Meshaal IA, Tariq M, Parman NS, Woodhouse N. 1986. The antidiabetic activity of aloes: preliminary clinical and experimental observations. Hormone Res 24: 288-294.

6) Agarwal OP. 1985. Prevention of atheromatous heart disease. Angiology 36: 485-492.

7) Herlihy JT, Bertrand HH, Kim JD, Ikeno Y, Yu BP. 1998. Effects of aloe vera ingestion in the rat. I. Growth, food and fluid intake and serum chemistry. Phytother Res 12 : 183-188.

8) IkenoY, Hubbard GB, Lee MS, Yu BP, Herlihy JT. 2001.The influence of long term aloe ingestion on agerelated disease in male Fischer 344 rats. Phytother Res in press.

9) Davis RH, Leitner MG, Russo JM, Byrne ME. 1989. Wound healing. Oral and topical activity of aloe vera. J Am Podiatry Med Assoc 79: 559-562.

10) Hutter JA, Salman M, Stavinoha WB, Satsangi N, Willims RF, Streeper RT, Weintrub ST. 1996. Antiinflammatory C-glucosyl chromone from Aloe barbardensis. J Nat Prod 59: 541-543.

11) Hart LA, Nibbering PH, Labadie RP. 1990. Effects of low molecular constituents from Aloe vera gel on oxidative metabolism and cytotoxic and bactericidal activities of human neutrophils. Int J Immunopharmacol 12: $427-$ 434.

12) Hart LA, van den Berg AJ, Kuis L, van Dijk H, Labadie RP. 1989. An anti-complementary polysaccharide with immunological adjuvant activity from the leaf parenchyma gel of aloe vera. Planta Med 55: 509-512.

13) Hart L.A., van Enckevort, P.H., van Dijk, H., Zaat, R., de Silvia, K.T., Labadie, R.P., 1988. Two functionally and chemically distinct immunomodulatory compounds in the gel of aloe vera. J Ethnopharmacol 23: 61-71.

14) Penneys NS. 1982. Inhibition of arachidonic acid oxidation in vitro by vehicle components. Acta DermatoVenerelogica 62: 59-61.

15) Herlihy JT, Kim JD, Kalu DN, Nelson JF, Ward W F, Ikeno Y, Yu BP. 1998. Effects of aloe vera ingestion in the rat.
II. Hormonal and metabolic characteristics. Phytother Res 12: 355-360.

16) Lee KY, Weintrub S, Yu BP. 2000. Isolation and identification of a phenolic antioxidant from Aloe barbadensis. Free Rad Biol Med 28: 261-265.

17) Yu BP. 1994. Cellular defenses against damage from reactive oxygen species. Physiol Rev 74: 139-162.

18) Choi HY, Song JH, Park DK. 1998. A combined flow injection-chemiluminescent method for the measurement of radical scavenging activity. Anal Biochem 264: 291-293.

19) Choi HY, Jhun EJ, Lim BO, Chung IM, Kyung SH, Park DK. 2000. Application of flow injection-chemiluminescene to the study of radical scavenging activity in plants. Phytother Res 14: 250-253.

20) Yu BP, Masoro EJ, Murata I, Bertrand BA, Lynd FT. 1982. Life span study of SPF Fischer 344 male rats fed ad libitum or restricted diets: longevity, growth, lean body mass and diseases, J Gerontol 37: 130-141.

21) Folch J, Lees M, Sloane-Stanley GH. 1957. A simple method for the isolation and purification of total lipids from animal tissues. J Biol Chem 226: 497-509.

22) Miyazawa T, Suzuki T, Fujimoto K, Yasuda K. 1992. Chemiluminesecent simultaneous determination of phosphatidylcholine hydroperoxide and phosphatidylethanolamine hydroperoxide in the liver and brain of the rat. J Lipid Res 33: 1051-1059.

23) Terao J, Piskula M, Yao Q. 1994. Protective effect of epicatechin, epicatechin gallate, and quercetin on lipid peroxidation in phospholipid bilayers. Arch Biochem Biophys 308: 278-284.

24) Lee DW, Yu BP. 1990. Modulation of free radicals and superoxide dismutase by age and dietary restriction. Aging Clin Exp Res 2: 357-362.

25) Aebi H. 1984. Catalase in vitro. Methods Enzymol 105: 121-126.

26) Beers RF, Sizer IW. 1952. A Spectrophotometric Method for Measuring the Breakdown of Hydrogen Peroxide by Catalase. J Biol Chem 195: 133-140.

27) Gu JY, Wakizono Y, Tsujita A, Lim BO, Nonaka M, Yamada K, Sugano M. 1995. Effects of sesamin and $\alpha$ tocopherol, individually or in combination, on the polyunsaturated fatty acid metabolism, chemical mediator production, and immunoglobulin levels in SpragueDawley rats, Biosci Biotech Biochem 59: 2198-2202.

28) Nagata Y, Imaizumi K, Sugano M. 1980. Effect of soyabean protein and casein on serum cholesterol levels in rats. Br J Nutr 44: 113-121.

29) Sperry WM, Merrill W. 1950. A revision of the schoenheimer-sperry method for cholesterol determination. $J$ Biol Chem 187: 97-106.

30) Duncan DB. 1955. Multiple range and multiple F test. Biometrics 11: 1-42.

31) Klein AD, Pennys NS. 1988. Aloe vera. J Am Acad Dermatol 18: 714-720.

32) Lim BO, Yu BP, Cho SI, Her E, Park DK. 1998. The inhibition by quercetin and Ganhuangenin on oxidatively modified low-density lipoprotein. Phytother Res 12: 340-345.

33) Lim BO, Yu BP, Oh JH, Park DK. 1988. The inhibitory effects of ginsenoside and quercetin on oxidatively damage by puromycin aminonucleoside in rat. Phytother Res 12: $375-377$.

34) Lim BO, Yu BP, Kim SC, Park DK. 1999. The antioxidative effect of ganhuangenin against lipid peroxdiation. 
Phytother Res 13: 479-483.

35) Lim BO. 2002. Effect of ganhuangenin obtained from Scutellaria radix on chemical mediator production of peritoneal exudates cells and immunoglobulin E level of mesenteric lymph node lymphocytes in Sprague-Dawley rats. Phytother. Res. 16: 166-170.

36) Kim SC, Choi OB, Oh JH, Park DK. 1996. Effects of ganhuangenin obtained from Scutellaria Baicalensis Georgi on the peroxidation of phospholipid. Inter Soc for Free Radic Res 8: 114 (Abstract).

37) Saito H, Ishiguro T, Imanishi K, Suzuki I. 1982. Pharmacological studies on a plant lectin aloctin A. II. Inhibitory effect of aloctin A on experimental models of inflammation in rats. Jpn J Pharmacol 32: 139-142.

38) Yu BP. 1996. Aging and oxidative stress: modulation by dietary restriction. Free Radic Biol Med 21: 651-668. 